\title{
Improving Environmental and Social Targeting through Adaptive Management in Mexico's Payments for Hydrological Services Program
}

\author{
KATHARINE R. E. SIMS, ${ }^{*}$ ๆ JENNIFER M. ALIX-GARCIA, $†$ ELIZABETH SHAPIRO-GARZA, $\neq$ \\ LEAH R. FINE, ${ }^{*}$ VOLKER C. RADELOFF, $₫$ GLEN ARONSON, $₫$ SELENE CASTILLO, $\neq$ \\ CARLOS RAMIREZ-REYES, $₫$ AND PATRICIA YAÑEZ-PAGANS $\dagger$ \\ ${ }^{*}$ Economics and Environmental Studies, Amherst College, P.O. Box 5000, Amherst, MA 01002, U.S.A. \\ †Agricultural and Applied Economics, University of Wisconsin-Madison, 417 Taylor Hall, Madison, WI 53706, U.S.A. \\ $\ddagger$ Nicholas School of the Environment, Duke University, Box 90328, Durham, NC 27708, U.S.A. \\ §Forest and Wildlife Ecology, University of Wisconsin-Madison, 1630 Linden Drive, Madison, WI 53706, U.S.A.
}

\begin{abstract}
Natural resource managers are often expected to achieve both environmental protection and economic development even when there are fundamental trade-offs between these goals. Adaptive management provides a theoretical structure for program administrators to balance social priorities in the presence of trade-offs and to improve conservation targeting. We used the case of Mexico's federal Payments for Hydrological Services program (PSAH) to illustrate the importance of adaptive management for improving program targeting. We documented adaptive elements of PSAH and corresponding changes in program eligibility and selection criteria. To evaluate whether these changes resulted in enrollment of lands of bigh environmental and social priority, we compared the environmental and social characteristics of the areas enrolled in the program with the characteristics of all forested areas in Mexico, all areas eligible for the program, and all areas submitted for application to the program. The program successfully enrolled areas of both high ecological and social priority, and over time, adaptive changes in the program's criteria for eligibility and selection led to increased enrollment of land scoring bigh on both dimensions. Three factors facilitated adaptive management in Mexico and are likely to be generally important for conservation managers: a supportive political environment, including financial backing and encouragement to experiment from the federal government; availability of relatively good social and environmental data; and active participation in the review process by stakebolders and outside evaluators.
\end{abstract}

Keywords: conservation targeting, forest conservation, Latin America, payments for ecosystem services

Mejorando los Objetivos Ambiental y Social Mediante el Manejo Adaptativo en el Programa de Pagos por Servicios Hidrológicos en México

Resumen: Continuamente se espera que los administradores de recursos naturales obtengan tanto protección ambiental como desarrollo económico cuando bay contraposiciones fundamentales entre esas metas. El manejo adaptativo proporciona una estructura teórica para que los administradores de programas puedan balancear prioridades sociales en la presencia de contraposiciones y mejorar los objetivos de conservación. Usamos el caso del Programa Federal de Pagos por Servicios Hidrológicos (PSAH, en inglés) en México para ilustrar la importancia del manejo adaptativo para la mejoría de los objetivos del programa. Documentamos los elementos adaptativos del PSAH y los cambios correspondientes en la elegibilidad del programa y los criterios de selección. Para evaluar si estos cambios resultaban en la inscripción de tierras con alta prioridad social y ambiental, comparamos las características sociales y ambientales de las áreas enlistadas en el programa con las características de todas las áreas forestales en México, todas las áreas elegibles 
para el programa y todas las áreas presentadas para aplicación en el programa. El programa enlistaba exitosamente áreas de prioridad social y ecológica, y con el tiempo, los cambios adaptativos en los criterios del programa para la elegibilidad y la selección llevaron a la inscripción incrementada de tierras con puntajes altos en ambas dimensiones. Tres factores facilitaron el manejo adaptativo en México y probablemente sean importantes para los administradores de la conservacion: un ambiente político de apoyo, incluyendo apoyo financiero y estímulo para experimentar por parte del gobierno federal; disponibilidad de datos sociales y ambientales relativamente buenos; y participación activa en el proceso de revisión por parte de los depositarios y evaluadores externos.

Palabras Clave: Conservación de bosques, Latinoamérica, objetivos de conservación, pagos por servicios ambientales

\section{Introduction}

Managers of payments for ecosystem services (PES) programs are increasingly expected to achieve both environmental protection and economic development, although in many cases there are fundamental trade-offs between these goals. Efforts to preserve valuable ecosystems will be most effective if they target areas with the highest risk of loss (Shogren et al. 1999), but these lands are often also the most productive and are owned by middle- or highincome landowners. Targeting of conservation payments based on environmental goals alone may therefore exacerbate an unequal distribution of wealth (e.g., Pagiola et al. 2005; Jack et al. 2008; Wunder 2008). Conservation practitioners concerned about social objectives thus need management tools that can help balance multiple priorities. Further, given the complex and dynamic nature of both threats to ecosystems and social objectives, these tools must allow managers to adjust in response to new evidence so as to improve targeting over time.

Adaptive management may provide such a structure by treating policy choices as deliberate experiments; requiring a continuous loop of program design, implementation, monitoring, evaluation, and redesign in response to evidence and stakeholder feedback. Yet despite a rich theoretical literature, there is little empirical evidence that adaptive management works in practice to improve conservation. We used the case of Mexico's federal Payments for Hydrological Services program (PSAH) to study the importance of adaptive management for achieving the goal of enrolling lands of high environmental and social priority. The program is implemented by the Mexican National Forestry Commission (CONAFOR) and compensates landowners for maintaining forest cover on their land under 5-year contracts. Mexico's program is an important case because it is increasingly common for PES programs, particularly in developing countries, to attempt to achieve both conservation and rural poverty alleviation (Pagiola et al. 2005; Muradian et al. 2010).

\section{Program Goals and Structure}

Mexico's PSAH program is one of the first and largest efforts to implement a national-scale PES program (Fig. 1;
Supporting Information). The program began in 2003 with the primary goal of conserving forests to improve water quality and quantity for downstream communities and secondary social goals of maintaining rural incomes and reducing poverty. Between 2003 and 2010, over 3,300 properties were enrolled in the program ( $>2.3$ million ha). The original name of the program was Pagos por Servicios Ambientales Hidrológicos (PSAH). The program subsequently became part of a larger forestry support program (ProÁrbol); we retained the original name for clarity.

The program provides enrolled landowners with annual payments contingent on maintaining forest cover. Landowners apply voluntarily, and parcels selected from those eligible for the program are enrolled for 5 years under a single contract. Until 2010, payments were offered on a 2 -tier scale of approximately US $\$ 36 /$ ha for cloud forest and US\$27/ha for other forest types. Cloud forest payments were higher due to this forest type's perceived greater capacity to provide hydrological services (MuñozPiña et al. 2008). In addition to per-hectare payments, the program encourages sustainable forest management by requiring and providing funds to hire technical advisors to deliver training and create forest management plans. Both individually held lands and communal properties are eligible for the program and recipients choose freely how to spend the funds they receive.

\section{Adaptive Management}

Adaptive management provides a framework that treats policy as a deliberate experiment and responds to changing conditions on the basis of the best available evidence (Halbert 1993; Folke et al. 2005). Originally developed to manage uncertain and complex ecological systems (Holling 1978; Walters 1986; Walters and Holling 1990), adaptive management theory has since been extended to policy processes governing combined social and ecological systems and co-managed or community-based conservation (e.g., Berkes et al. 2000; Folke et al. 2005; Westgate et al. 2013).

Little consensus exists on the exact definition of adaptive management. Early literature emphasizes flexibility, defining adaptive management as learning 


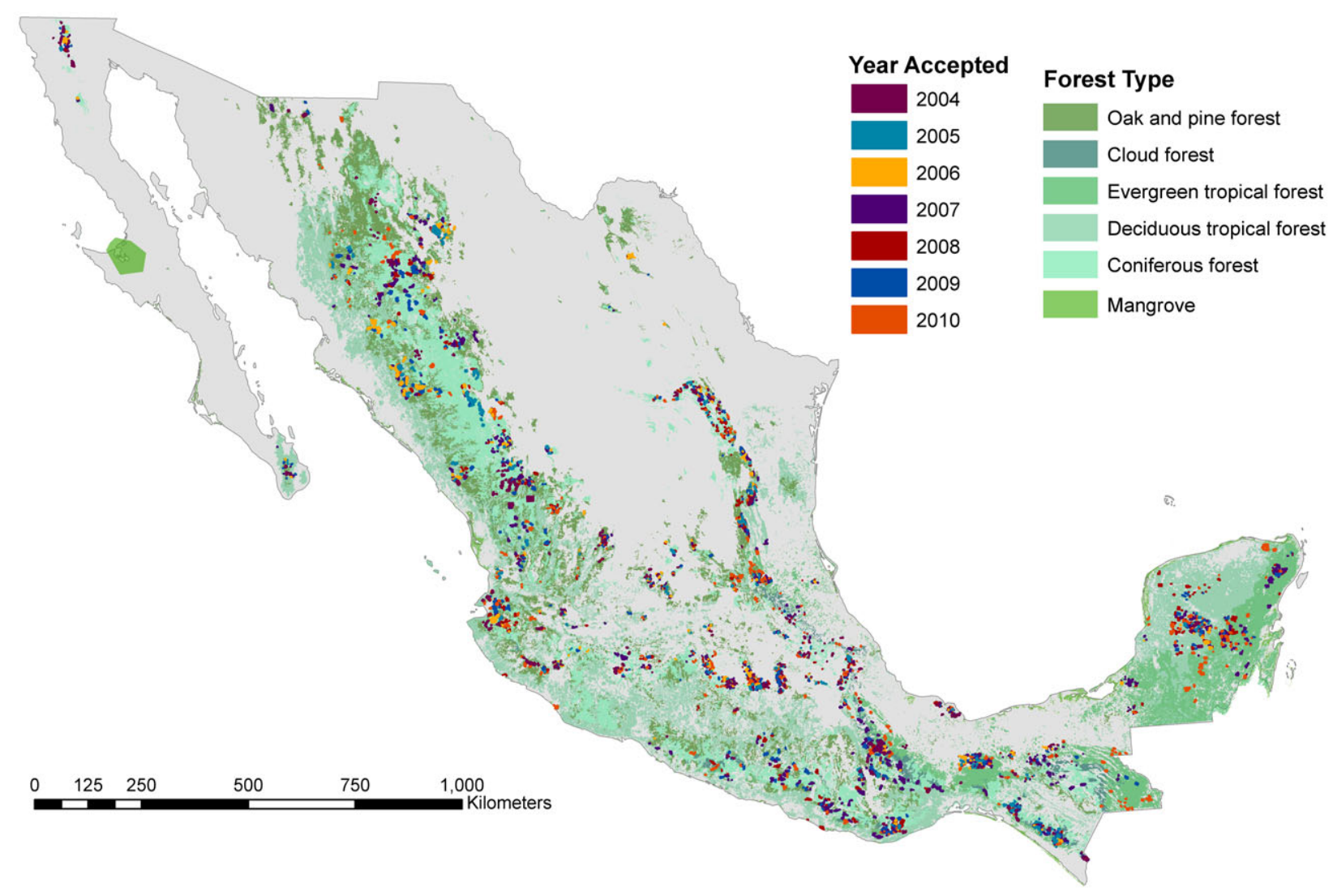

Figure 1. Parcels enrolled in Mexico's Payments for Hydrological Services Program from 2004 to 2010. Data on parcel boundaries is from the Mexican National Forestry Commission, and data on forest types is from the Mexican National Institute of Statistics and Geography Series III.

by doing or management by experiment (Walters 1986; Walters \& Holling 1990). More recent publications stress the importance of "systematic acquisition and application of reliable information" (Wilhere 2002, p. 20; Williams et al. 2009). Three defining features are consistent in previous literature: experimental program design, systematic monitoring and evaluation of impacts, and continuous redesign of policy in response to evidence and feedback from stakeholders (e.g., Gunderson 1999; Wilhere 2002; Folke et al. 2005; Nie \& Shultz 2012, Rist et al. 2012; Westgate et al. 2013).

Although there has been extensive theoretical research on adaptive management, there are few empirical assessments of its implementation, particularly in middle-income and developing countries. Early adaptive management literature focuses on fisheries in Australia and the United States (e.g., Halbert 1993; Peterman and Peters 1998; Lee 1999). More recently, adaptive management has been applied in the United States in the Florida Everglades, forests of the Pacific Northwest, and riparian areas in the Grand Canyon (e.g., NRC 2004; Nie and Schultz 2012). Studies of implemented adaptive management programs are still relatively rare. Recent reviews show that only 5-13\% of the literature focuses on actual adaptive management programs, rather than theoretical discussions (McFadden et al. 2011; Rist et al. 2012; Westgate et al. 2013). There is, then, a need for further study to examine the conditions under which implementation can be successful.

\section{Elements of Adaptive Management in PSAH}

To categorize changes in the eligibility and selection criteria for the PSAH program (Table 1), we reviewed annually published rules of operation from CONAFOR. We also interviewed key actors at multiple levels who had been involved in the policy process and reviewed the literature (Supporting Information). To our knowledge, program managers in Mexico did not use the term adaptive management to describe their approach. Nevertheless, the program has the 3 key elements of adaptive management.

First, PSAH incorporated elements of experimental program design. Although PSAH was initially proposed as a pilot program to allow for experimentation, it was scaled-up immediately to a nationwide level due to enthusiasm within the government. However, the earliest cohorts of the program were fairly small, and expansion of the program over time depended on results from earlier 
Table 1. Eligibility and selection criteria for Mexico's Payments for Hydrological Services Program, 2004-2010. ${ }^{a}$

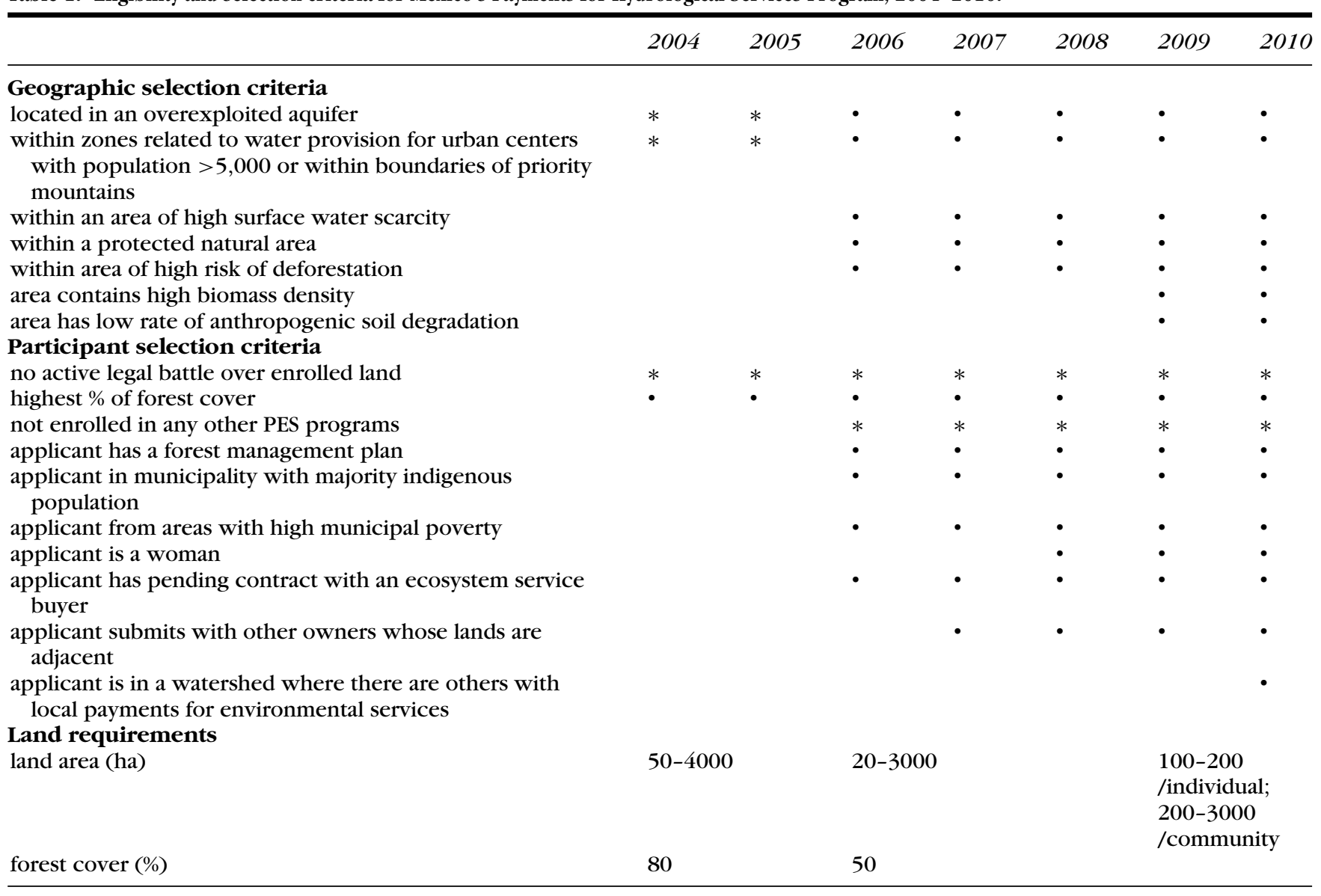

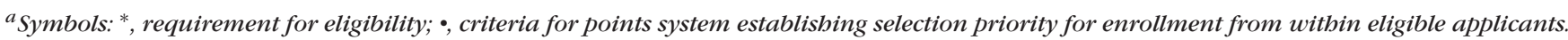

cohorts. In this sense, the first years of the program were used as experiments, though without formal randomization. In addition, program design was highly participatory from the start. A multistakeholder advisory committee included representatives of ecosystem services user and provider groups, different government agencies, and civil society organizations involved in environmental issues and rural development. As one civil society member of the original oversight committee explained, the purpose was to generate "a dialogue that combined the experience of government agencies and civil society organizations to create a program with real impact" (ShapiroGarza 2013, p. 142).

Second, adaptive management also requires systematic monitoring and evaluation of impacts and use of the results to inform changes to policy design in a continuous feedback loop. In the case of PSAH, program rules were revised each year by the implementing team at CONAFOR and reviewed and approved by the CONAFOR central administration. During the rule revision process, input was sought from outside groups, including state program administrators and the multistakeholder committee. In addition, CONAFOR was mandated by law to conduct annual external evaluations of their programs, which have been carried out by outside universities and consultants since the program began.

Finally, adaptive management needs progressive redesign of policy according to feedback from stakeholders and evaluations of program functionality and impacts. Over time CONAFOR made multiple changes in response to critiques. In the first years of the program (20032005), eligible land was required to be upstream from urban centers or inside priority mountain areas, to be above overexploited aquifers, and to have $>80 \%$ forest cover (Table 1). The eligible zones were small (Supporting Information), and within the pool of eligible applicants, priority was given to those with more forest cover. This system was criticized for not enrolling enough areas at high risk of deforestation and not reaching enough economically and socially marginalized communities. In response, PSAH program managers expanded the eligible zones (Supporting Information), allowed applications from smaller landholders, and changed the selection system. To increase the accuracy and transparency of the selection process, they created a new system in which they assigned points to applicants based on multiple criteria, including risk of deforestation, surface water scarcity, 
and location in a majority indigenous or high poverty municipality. The points system has allowed flexibility in setting priorities and introducing new criteria over time (Table 1).

In addition, civil society organizations argued that the initial rules on forest use were too prohibitive and that the $80 \%$ forest cover rule excluded some lower density forest types of high conservation value. Starting in 2006, CONAFOR lowered the requirement to $50 \%$ forest cover and put more emphasis on active and sustainable forest management activities. The new rules required participants to develop forest management plans and provided participants with funding for technical assistance for forest management activities.

Finally, one of the initial goals of the program was to induce independent markets for hydrological services. This goal was based on the idea that payments would be more sustainable in the long run if they came directly from local, downstream hydrological services users (Pagiola et al. 2002; Muñoz-Piña et al. 2008). However, after the initial 5-year contract period, few independent markets had formed. In response to pressure to continue contracts while still encouraging the development of local markets, CONAFOR allowed renewal and implemented a series of rules to encourage clustering of applicants within watersheds. In 2006, they assigned higher points to applicants with a pending contract with buyers. In 2007, they gave extra points for adjacent applicants who applied jointly, and in 2010 , they gave extra points for landowners within watersheds where there were local PES schemes supported by a CONAFOR matching funds program (Table 1).

CONAFOR faces a constant balancing act in trying to meet program goals, and not all changes have been retained over time. For instance, in 2009 parcel eligibility sizes were again increased, encouraging group applications in order to reduce transaction costs. At the same time, the maximum amount of land that could be enrolled by private property landowners, who tend to be wealthier, was reduced. In 2010 CONAFOR stopped expanding the eligible zones and began to downsize and re-prioritize them. In addition, the system transitioned from flat-rate payments to flexible dynamic payments based on local context, including forest types and the opportunity cost of foregone land conversion.

\section{Methods}

The goal of our quantitative analysis was to determine whether the program enrolled lands of ecological and social significance and to understand how the changes in the PSAH eligibility and selection rules affected the types of land ultimately enrolled. We used 2 data configurations (Supporting Information) to analyze program eligibility, selection, and enrollment. To evaluate enroll- ment outcomes overall from 2004 to 2010 , we compared characteristics of a random sample of areas from within the boundaries of enrolled land to a random sample of areas from within the boundaries of all land submitted for application to the program and a random sample of areas from within all forested land in Mexico (Fig. 2; Supporting Information). To evaluate how changes in program management led to changes in selection of areas over time, we analyzed environmental and social characteristics for areas eligible for the program for all enrolled parcels and for parcels that were submitted for application for each program cohort from 2004 to 2010 (Fig. 3; Supporting Information).

Successful enrollment of land with high priority for hydrological services was assessed on the basis of its surface water availability, overlap with an overexploited aquifer, and forest type. Deforestation risk was assessed using INECC's version 1 index and characteristics associated with risk of deforestation. Lands with steeper slopes, high elevation areas, and areas farther from population centers are generally at a lower risk of deforestation due to the difficulty of converting land to agriculture, grazing, or forestry (Alix-Garcia et al. 2008; Muñoz-Piña et al. 2008). General environmental priority was assessed on the basis of whether lands were located in a priority mountain or protected natural area and social priority was assessed on the basis of municipal poverty index, location in a majority indigenous municipality, and location in a common property.

\section{Results}

Overall, from 2004 to 2010, CONAFOR successfully recruited and enrolled areas of general environmental concern and areas with high importance for hydrologic services (Fig. 2). Relative to all forested lands and lands submitted for application, enrolled PSAH lands were more frequently located within overexploited aquifers, priority mountain areas, and protected natural areas. The mean surface water availability for PSAH lands was lower than that for all forested lands, and PSAH lands were on average closer to localities with a population over 5,000, where demand for hydrologic services is high. Enrolled parcels on average also had more cloud forest than all forested areas and areas submitted for application.

We found that higher deforestation risk areas were selected from the pool of possible applicant areas, but the pool had on average a lower risk of deforestation than all forested areas in Mexico. The mean risk of deforestation index for all enrolled PSAH lands was 2.49 (out of 5), which was slightly greater than the mean for lands for which applications were submitted (difference of 0.03 SD) but less than the mean for all forested lands (2.85). For other characteristics associated with deforestation risk, results were mixed: PSAH lands were at higher 


\section{Environmental Characteristics}

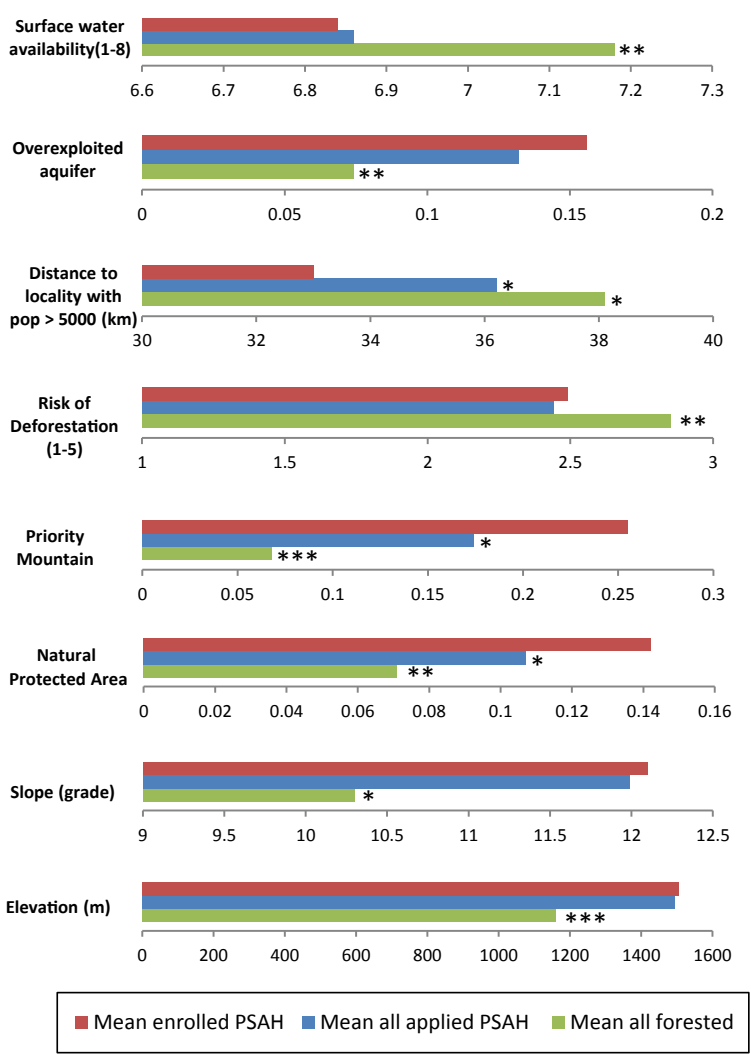

Social Characteristics

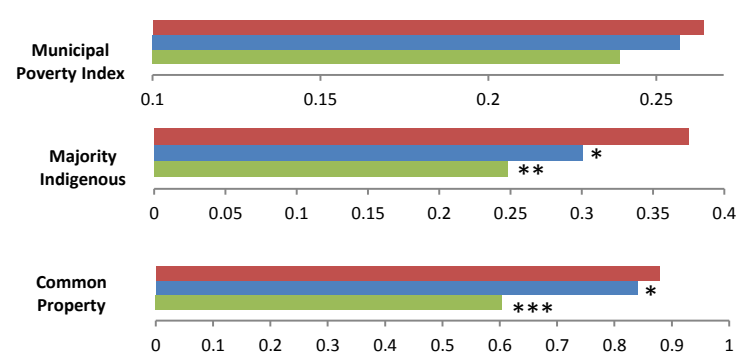

Forest Type
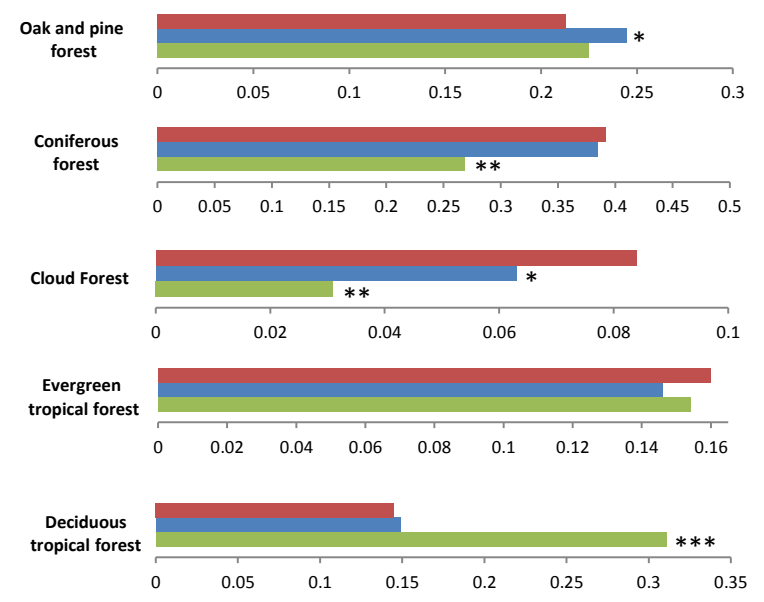

Figure 2. Environmental and social characteristics of areas enrolled in Mexico's Payments for Hydrological Services Program (PSAH), areas which were submitted for application to the program, and all forested lands in Mexico (2004-2010). Data sources and normalized differences in means are in Supporting Information. Asterisks indicate size of normalized differences between enrolled areas, areas submitted for application, and all forested lands: *0.05-0.15SD; ** 0.15-0.25SD; ***>0.25 SD.

elevation and had steeper slopes than all forested areas and areas submitted for application, but they were closer to population centers.

With respect to social priorities, recruitment to the applicant pool and selection for enrollment was successful (Fig. 2). The mean municipal poverty index for PSAH lands was slightly higher than the national average for all forested lands and all lands in the applicant pool. Enrolled lands were almost 0.2 SDs more likely to be in municipalities with a majority indigenous population than all forested lands. In addition, PSAH enrolled areas were substantially more likely to be in communally held properties than forests at large. Because on average households in common properties were less well-off than private landowners, the differences indicate overall success in enrolling more marginalized areas.

Changes in program targeting criteria generally increased the enrollment of lands scoring high in terms of both ecological and social priority over time (Fig. 3). With respect to the risk of deforestation among enrolled parcels, the distribution shifted right, and the index values increased by 0.08 points/year on average (Fig. 3,
Supporting Information). The largest increases followed the substantial rule changes introduced in 2006 . The average slope and elevation of enrolled properties also decreased significantly across time, indicating enrollment of higher-risk properties (Supporting Information). Similarly, enrollment of land in higher poverty areas increased significantly over time; the average increase in the municipal poverty index was $0.078 /$ year (Fig. 3; Supporting Information). As with deforestation risk, there were significant shifts in the distribution of municipal poverty concentrated in the post-2006 period (Fig. 3).

Improvements in enrollment of lands with high priority environmental and social characteristics were due to changes in both eligibility and selection criteria. In areas eligible for the program, mean values for the risk of deforestation increased over time (by 0.105 points/year), indicating efforts to recruit applications from areas of higher risk (Supporting Information). The mean values of the poverty index within each year's eligible zones also increased significantly over time ( 0.088 points on average); the largest increase occurred from 2006 to 2007. Levels were high in 2008 and 2009 and decreased in 

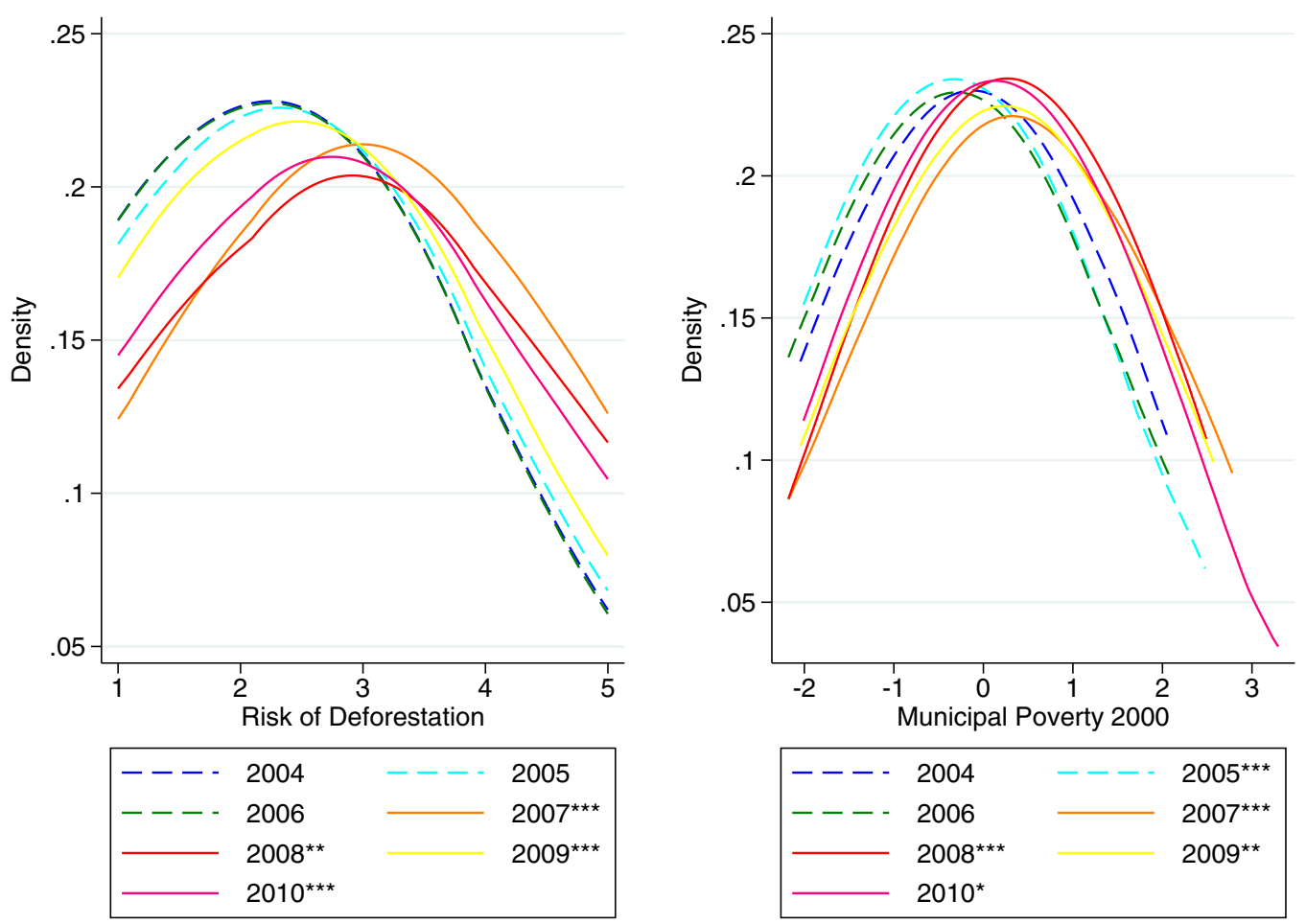

Figure 3. Smoothed distribution of risk of deforestation index and municipal poverty index for areas enrolled in each cohort of Mexico's Payments for Hydrological Services Program from 2004 to 2010. Asterisks indicate the $\mathrm{p}$ values from a Kolmogorov-Smirnov test for equality of distribution between that year and the prior year: ${ }^{* *} \mathrm{p}<$ $0.05 ;{ }^{* * *} \mathrm{p}<0.01$.

2010. The likelihood of an eligible area being within a majority indigenous municipality or a common property also significantly increased over time (Supporting Information).

With respect to selection from within the pool of applications, the differences in deforestation risk between enrolled areas and applicant-pool areas were generally negative in the early years of the program but positive after 2006 (Supporting Information), indicating increasing efforts to select higher risk properties from the applicant pool over time. The difference in poverty indexes between accepted and applicant-pool land also increased in the later years of the program (Supporting Information), indicating that CONAFOR increased selection of poorer applicants from within the available pool. Similarly, there was an increase in the proportion of enrolled properties within majority indigenous municipalities and in the difference between accepted applications and all applications. At the same time these improvements were made, there was little change in enrollment of areas of particular environmental and hydrological concern (Supporting Information). This indicates that CONAFOR was able to maintain the selection of high priority areas for these environmental characteristics while generally increasing the average risk of deforestation and the poverty index of enrolled parcels.

\section{Discussion}

Our results demonstrate that PSAH increasingly enrolled areas of high ecological and social priority over time in response to policy adjustments driven by adaptive feedback loops. Our qualitative analysis suggests 3 factors facilitated this adaptive management in Mexico.

The first important factor was a political environment that encouraged experimentation and critical thinking. Because CONAFOR was a relatively new government agency, formed in 2001, it had little entrenched bureaucracy and thus attracted innovators from academia and the rural forestry sector. This brought an infusion of new ideas into the design and implementation of the PSAH program. PSAH also benefited from political support and relative funding security. From 2006 to 2012, the program continued to receive financial and political support from the government. The majority of funds were generated from a federal tax on water use, and CONAFOR established an innovative government-managed trust fund that allowed them to set aside the full 5 years of funding when contracts were signed, ensuring that funds would be available regardless of changes in political will or budgets. These findings are consistent with previous research that suggests adaptive management requires long-term political and financial support so that time-consuming 
feedback and redesign cycles can be planned and enacted (Holling 1993; Holling and Meffe 1996; Gunderson 1999).

A second key factor facilitating adaptive management in Mexico was the availability of relatively high quality data and technical capacity. Compared with other lowand middle-income countries, Mexico has strong information systems and significant expertise in evaluation. For example, censuses have been conducted on average every 10 years since 1900 , and this information is publicly available. This enables long-term tracking of social targeting data, such as the degree of poverty or the location of indigenous populations. In addition, the government has created and substantially funded a ministry to support evaluation of government programs (CONEVAL) and has a government-funded environmental think tank for the study of ecology and climate (INECC). Both have worked with CONAFOR in providing information for targeting and in analyzing the PSAH program.

Finally, stakeholder participation in the design and implementation process is important for meaningful adaptive management (Armitage et al. 2008; Stringer et al. 2011) and has been substantial in the design and redesign of the PSAH program. A primary factor that allowed strong participation was the opening of the Mexican political process in 2001, which included new transparency laws requiring all government agencies to share program policy design and implementation data (Heyer 2006). This has allowed participants and other stakeholders to provide informed critique to CONAFOR in part through the stakeholder advisory group that reviews and comments on all program redesigns. The federal-level PES team has also solicited feedback on proposed new rule changes from state-level CONAFOR teams that are on the frontlines of program implementation. In addition to officially mandated evaluations, CONAFOR has also encouraged external research on the program, and program managers have participated in exchanges with other governments operating PES programs (e.g., Brazil, Costa Rica, and Ecuador) in order to discuss best practices (FONAFIFO et al. 2012).

Despite these positive factors facilitating adaptive management, a major remaining barrier to adaptive management in Mexico and elsewhere is the lack of reliable, high-quality annual data on deforestation. Satellite remote sensing is the only feasible way to derive such data at a national scale. However, mapping land cover change poses several challenges, including data availability issues and difficulties with interpretation that are common in tropical countries. These include cloud cover that limits the utility of Landsat images and complex forest phenology. Many of Mexico's forests exhibit open canopies and low tree height, making them difficult to distinguish remotely; other forest grows rapidly, making it difficult to detect deforestation events (Meneses Tovar 2009). These problems are exacerbated by the fact that many land cover disturbance or degradation events are spa- tially small or may not affect the forest canopy. MODIS satellite data have full temporal and spatial coverage and have been used for preliminary analysis of the avoided deforestation impacts of PSAH (Alix-Garcia et al. 2012), but these data are of low resolution. Currently, however, high-resolution satellite sensors, such as SPOT, Quickbird, and IKONOS are expensive and do not have an image acquisition plan that would cover the entire country annually. Future adaptive management of PSAH or other land conservation programs would benefit substantially from investment in new information technologies such as radar-based sensing and analysis of new data from the Landsat 8 OLI sensor.

In summary, our analysis of the patterns of enrollment in Mexico's PSAH indicates substantial success in enrolling lands with both high ecological and social priority. We also found that enrollment of lands with higher risk of deforestation and greater social importance increased over time. Improvements in targeting to enroll areas of high ecological and social priority in the PSAH program illustrate how the learning and reevaluation components of adaptive management, facilitated by significant stakeholder participation, can help to reduce trade-offs between multiple conservation objectives. However, rigorous analysis of whether PES goals have been achieved is still limited and ongoing (Ferraro 2011). Even in the presence of perfect monitoring, voluntary land conservation programs will naturally be plagued by the fact that those most likely to enroll are those who were unlikely to deforest their land in the first place. While better targeting of high deforestation risk areas based on real-time deforestation data or auctions to elicit the value of alternative uses (Ferraro 2008; Ajayi et al. 2012) may help address this issue, such targeting will be costly and rarely perfect. Adaptive management is thus likely to continue to play an important role in conservation efforts. In the case of Mexico's PSAH, we suggest that adaptive management of the program was facilitated by secure and long-term funding and support, access to reliable and timely geographic and demographic data, and a political and bureaucratic environment that included stakeholder participation in policy design and outside evaluation. These policy conditions are likely to be generally important for successful implementation of PES and other land conservation programs seeking to use adaptive management to balance ecological and social priorities.

\section{Acknowledgments}

We thank the Mexican National Forestry Commission for their generous sharing of time, expertise, and data. We thank the University of Wisconsin, Duke University, Amherst College, the International Initiative for Impact Evaluation (3ie), and the National Science Foundation (grant 1061852) for financial support. 


\section{Supporting Information}

Supplemental description of quantitative methods (Appendix S1), PSAH eligible zones (Appendix S2), total enrollments and payments (Appendix S3), data sources and characteristics of eligible zones (Appendix S4), characteristics of all enrolled areas, all forested areas, and all areas in the applicant pool (Appendix S5), characteristics of enrolled parcels and parcels in the applicant pool for each cohort (Appendix S6), descriptions of qualitative sources, methods, and characteristics of program administrators interviewed and references not included in the article (Appendix S7) are available online. The authors are solely responsible for the content and functionality of these materials. Queries (other than absence of the material) should be directed to the corresponding author.

\section{Literature Cited}

Ajayi, O. C., B. K. Jack, and B. Leimona. 2012. Auction design for the private provision of public goods in developing countries: lessons from payments for environmental services in Malawi and Indonesia. World Development 40:1213-1223.

Alix-Garcia, J., A. De Janvry, and E. Sadoulet. 2008. The role of deforestation risk and calibrated compensation in designing payments for environmental services. Environment and Development Economics 13:375-394.

Alix-Garcia, J. M., E. N. Shapiro, and K. R. Sims. 2012. Forest conservation and slippage: evidence from Mexico's national payments for ecosystem services program. Land Economics 88:613-638.

Armitage, D., M. Marschke, and R. Plummer. 2008. Adaptive co-management and the paradox of learning. Global Environmental Change 18:86-98.

Berkes, F., J. Colding, and C. Folke. 2000. Rediscovery of traditional ecological knowledge as adaptive management. Ecological Applications 10:1251-1262.

Ferraro, P. J. 2008. Asymmetric information and contract design for payments for environmental services. Ecological Economics 65:810821.

Ferraro, P. J. 2011. The future of payments for environmental services. Conservation Biology 25:1134-1138.

Folke, C., T. Hahn, P. Olsson, and J. Norberg. 2005. Adaptive governance of social-ecological systems. Annual Review of Environment and Resources 30:441-473.

FONAFIFO, CONAFOR, and Ecuador Ministry of Environment. 2012. Lessons learned for REDD+ from PES and conservation incentive programs. Examples from Costa Rica, Mexico, and Ecuador. Forest Trends.

Gunderson, L. 1999. Resilience, flexibility and adaptive management antidotes for spurious certitude? Ecology and Society 3:7.

Halbert, C. L. 1993. How adaptive is adaptive management? Implementing adaptive management in Washington State and British Columbia. Reviews in Fisheries Science 1:261-283.

Heyer, E. 2006. Latin American state secrecy and Mexico's transparency law. George Washington International Law Review 38:437-475.

Holling, C. S. 1978. Adaptive environmental assessment and management. Wiley-Interscience, United Kingdom.

Holling, C. S. 1993. Investing in research for sustainability. Ecological Applications 3:552-555.

Holling, C. S. and G. K. Meffe. 1996. Command and control and the pathology of natural resource management. Conservation Biology 10:328-337.
Jack, B. K., C. Kousky, and K. R. E. Sims. 2008. Designing payments for ecosystem services: lessons from previous experience with incentive-based mechanisms. Proceedings of the National Academy of Sciences 105:9465-9470.

Lee, K. N. 1999. Appraising adaptive management. Conservation Ecology $3: 3$.

McFadden, J. E., T. L. Hiller, and A. J. Tyre. 2011. Evaluating the efficacy of adaptive management approaches: Is there a formula for success? Journal of Environmental Management 92:1354-1359.

Meneses Tovar, C. L. 2009. Analysis of the normalized differential vegetation index (NDVI) for the detection of degradation of forest coverage in Mexico 2008-2009. Working Paper No. 173. FAO Forest Resources Assessment.

Muñoz-Piña, C., A. Guevara, J. Torres, and J. Braña. 2008. Paying for the hydrological services of Mexico's forests: analysis, negotiations and results. Ecological Economics 65:725-736.

Muradian, R., E. Corbera, U. Pascual, N. Kosoy, and P. H. May. 2010. Reconciling theory and practice: an alternative conceptual framework for understanding payments for environmental services. Ecological Economics 69:1202-1208.

National Research Council. 2004. Adaptive management for water resource project planning. National Academies Press, Washington, D.C.

Nie, M. A. and C. A. Schultz. 2012. Decision-making triggers in adaptive management. Conservation Biology 26:1137-1144.

Pagiola, S., A. Arcenas, and G. Platais. 2005. Can payments for environmental services help reduce poverty? An exploration of the issues and the evidence to date from Latin America. World Development 33:237-253.

Pagiola, S., J. Bishop, and N. Landell-Mills. 2002. Selling forest environmental services: market-based mechanisms for conservation and development. Earthscan, London, United Kingdom.

Peterman, R. M. and C. N. Peters. 1998. Decision analysis: taking uncertainties into account in forest resource management. Pages 105128 in V. Sit and B. Taylor, editors. Statistical methods for adaptive management studies. Land management handbook no. 42. Ministry of Forests Research Branch, Victoria, British Columbia.

Rist, L., B. M. Campbell, and P. Frost. 2012. Adaptive management: Where are we now? Environmental Conservation 40:5-18.

Shapiro-Garza, E. 2013. Contesting market-based conservation: payments for ecosystem services as a surface of engagement for rural social movements in Mexico. Human Geography 6:134-150.

Shogren, J. F., J. Tschirhart, T. Anderson, A. W. Ando, S. R. Beissinger, D. Brookshire, G. M. Brown, D. Coursey, R. Innes, and S. M. Meyer. 1999. Why economics matters for endangered species protection. Conservation Biology 13:1257-1261.

Stringer, L. C., A. J. Dougill, E. Fraser, K. Hubacek, C. Prell, and M. S. Reed. 2011. Unpacking 'participation' in the adaptive management of social-ecological systems: a critical review. Ecology and Society 11:39.

Walters, C. 1986. Adaptive management of renewable resources. Macmillan Publishing Company, New York.

Walters, C. J. and C. S. Holling. 1990. Large-scale management experiments and learning by doing. Ecology 71:2060-2068.

Westgate, M. J., G. E. Likens, and D. B. Lindenmayer. 2013. Adaptive management of biological systems: a review. Biological Conservation 158:128-139.

Wilhere, G. F. 2002. Adaptive management in habitat conservation plans. Conservation Biology 16:20-29.

Williams, B. K., R. C. Szaro, and C. D. Shapiro. 2009. Adaptive management: the US department of the interior technical guide. US Department of the Interior, Adaptive Management Working Group, Washington, D.C.

Wunder, S. 2008. Payments for environmental services and the poor: concepts and preliminary evidence. Environment and Development Economics 13:279-297. 